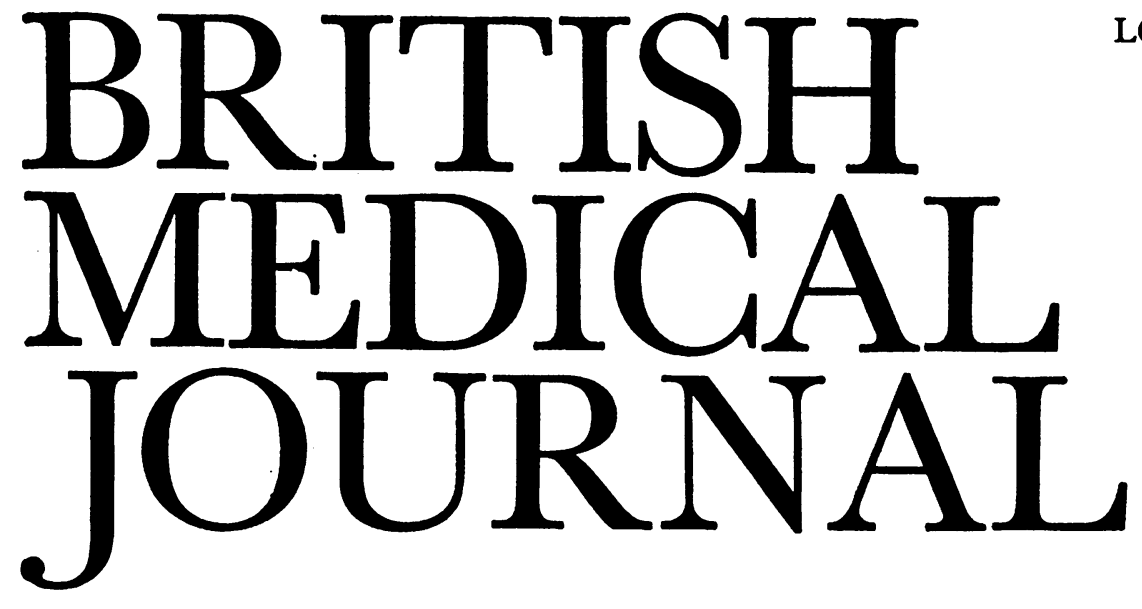

LONDON, SATURDAY 5 FEBRUARY 1977

\title{
Alopecia areata
}

The diagnosis of alopecia areata is usually straightforward, but its course is often unpredictable and the condition is certainly frustrating to treat. In the nineteenth century it was commonly confused with ringworm, partly because of inconsistencies in nomenclature and also because of inadequate mycological techniques. By 1900 most authorities had accepted that this form of alopecia was not an infection but otherwise found few areas of agreement about its cause. The "trophoneurotic" theory was sufficiently indefinite and adaptable to subsume later concepts such as reflex irritation, focal sepsis, and stress reactions.

Clinical associations with alopecia areata have been known for many years. In particular, thyroid disease has been found in a variable proportion of patients (of both sexes and a wide age range) with the condition. ${ }^{12}$ Some studies, however, have failed to confirm this overlap. ${ }^{3-5}$ A family history of diabetes is more commonly given by patients with alopecia areata than by controls with psoriasis. ${ }^{2}$ Further associations are suggested by the established link between alopecia areata and vitiligo, which occurs in about $4 \%$ of patients with alopecia and about $1 \%$ of controls. Vitiligo is known to be associated with thyroid disease, pernicious anaemia, and diabetes mellitus. ${ }^{6}$

The search for autoantibodies in patients with alopecia areata has also given conflicting results. A general increase in autoantibodies $^{7}$ and an increase restricted to antibodies to smooth muscle ${ }^{4}$ have both been reported. Even so, most authorities ${ }^{2} 58$ consider that quantitative estimates have failed to establish a significant or consistent rise in any autoantibody titre.

In 1965 Wunderlich and Braun-Falco ${ }^{9}$ showed that patients with Down's syndrome had a raised incidence of alopecia areata, ${ }^{5}$ but none of their patients was over 8 years old. Among 1000 children and adults with Down's syndrome Du Vivier and Munro ${ }^{10}$ found 60 cases of alopecia areata, of whom 25 had total or universal alopecia. In some of the girls and women affected antithyroid antibody titres were significantly increased as compared with controls. A recent American investigation $^{11}$ has confirmed the high incidence of alopecia areata in patients with Down's syndrome. Immunological abnormalities, notably $\mathrm{T}$-cell dysfunction, are known to be frequent in these patients. Among 214 examined 56.5\% had atopic dermatitis, but the authors failed to comment on this observation-and the total proportion recorded as atopic might have been higher still if other atopic manifestations had been noted. The association of alopecia areata with atopy has been recognised for some years. In one study the presence of dermatitis or asthma or both was recorded in $18 \%$ of children and $9 \%$ of adults with alopecia areata, and in $23 \%$ of children with alopecia totalis. ${ }^{1}$ Using different diagnostic criteria, studies have shown that $10 \%$ of patients in Japan with alopecia areata were atopic ${ }^{12}$ and $52.4 \%$ in Holland..$^{13}$

Investigators of the pathodynamics of hair shedding and prolonged inhibition of normal regrowth ${ }^{14}{ }^{15}$ have concluded that an insult - the nature of which is unknown-causes a transitory failure near the hair matrix. If the insult persists the follicles are held, sometimes indefinitely, in a state which corresponds to an early stage of anagen, with the result that they can produce only fine unpigmented down. The clinical associations and histological and pathodynamic studies have suggested that the mechanisms may be immunological. Those who believe in the autoimmune hypothesis often claim that the response of alopecia areata to corticosteroids supports them: yet only about $70 \%$ of cases respond even to systemic corticosteroids, ${ }^{16}$ and the response to intralesional corticosteroids ${ }^{17}$ is "all or nothing." 2 Many patients fail to show any response-usually those with atopic illness or with autoimmune disease themselves or in the family. ${ }^{12}$

Dermatologists have long considered that psychological factors play at least some part in precipitating attacks of alopecia areata. Indeed, most still hold this opinion ${ }^{18}$ - but not all psychiatrists agree. ${ }^{19}$ Even if stress does act as a precipitating or threshold factor that does not exclude immunological or other mechanisms.

The conclusions of so many reputable authors about so many aspects of alopecia areata are so contradictory and mutually irreconcilable that they encourage the belief that it must be heterogeneous. Ikeda ${ }^{12}$ of Japan was the first to put this hypothesis to the test by a prospective long-term study of a large number of cases. She classified her patients according to their associated abnormalities into four groups. Three were well defined: atopic $(10 \%)$; the endocrine autonomic $(5 \%)$, which we should now call the autoimmune group; and the common group $(81 \%)$. The age of onset, clinical features, prognosis, and response to treatment of these groups differed appreciably. Initially, Ikeda's ${ }^{12}$ contribution did not attract the attention it deserved, except from Professor Mali and his colleagues, ${ }^{1320}$ who have confirmed many of her findings.

Alopecia areata appears not to occur naturally in other 
mammals, though several conditions seem to duplicate some of its features. Attempts to produce alopecia areata in animals have been unconvincing, ${ }^{21}$ and hence we have to base our speculations on the confusing clinical evidence. Sadly, this leaves us with no satisfactory explanation for this tiresome condition.

1 Miller, S A, and Winkelman, R K, Archives of Dermatology, 1963, 88, 290. 2 Cunliffe, W C, et al, British fournal of Dermatology, 1969, 81, 879.

3 Salamon, T, Musafija, A, and Milikevic, M, Dermatologica, 1971, 142, 62.

${ }^{4}$ Main, R A, et al, British fournal of Dermatology, 1975, 92, 389.

5 Cochran, R E I, Thomson, J, and MacSween, R N M, British fournal of Dermatology, 1976, 95, 61.

6 Cunliffe, W J, et al, British fournal of Dermatology, 1968, 80, 135.

7 Kern, F, et al, Archives of Dermatology, 1973, 107, 407.

${ }^{8}$ Betterle, C, et al, Archives of Dermatology, 1975, 111, 927.

9 Wunderlich, C, and Braun-Falco, O, Medizinische Welt, 1965, 1, 477.

10 Vivier, A du, and Munro, D D, British Medical fournal, 1975, 1, 191.

11 Carter, D M, and Jegasothy, B V, Archives of Dermatology, 1976, 112, 1397.

12 Ikeda, T, Dermatologica, 1965, 131, 421.

13 Penders, A J M, Dermatologica, 1968, 136, 395.

14 Eckert, J, Church, R E, and Ebling, F J, British fournal of Dermatology, 1968, 80, 203.

${ }^{15}$ Ebling, F J, fournal of Investigative Dermatology, 1976, 67, 98.

${ }^{16}$ Duchková, H, Horáková, E, and Kulenda, Z, Ceskoslovenská Dermatologie, $1971,46,203$.

17 Porter, D, and Burton, J L, British fournal of Dermatology, 1971, 85, 272.

${ }_{18}$ Feldman, M, Rondon Lugo, A J, Medicina Cutanea, 1973, 7, 95.

19 Macalpine, I, British fournal of Dermatology, 1958, 70, 117.

${ }^{20}$ Mali, J W H, British fournal of Dermatology, 1975, 93, 605.

21 Thies, W, and Klaschka, F, Archiv fur Klinische und Experimentelle Dermatologie, 1970, 237, 51 .

\section{The old in the cold}

Our ideas about accidental hypothermia have changed greatly in the last two decades. Twenty years ago it was considered rare and almost confined to shipwrecked sailors, unlucky mountaineers, and the newborn. Then suddenly it was shown that, far from being rare, it was a common domestic disorder of the elderly ${ }^{1}$ and might itself be dangerous or might mask serious underlying disease. These facts have become increasingly acknowledged not only in Britain ${ }^{2-5}$ but in Europe ${ }^{6} 7$ and America. 89 The clinical features of hypothermia and the importance of suspicion and the use of a low-reading thermometer ${ }^{12}$ in making the diagnosis are now widely recognised.

In recent winters "hypothermia" has often been seen and heard in the popular news media, recently even on the lips of a comedian, and its prevalence has sometimes seemed the plaything of politicians. Yet there is still relatively little reliable information about its causes, its prevalence, or its mortality rate. There is clear evidence that many old people live in surroundings that are too cold ${ }^{10-12}$-sometimes even colder than the air temperatures laid down by law for young sedentary workers. ${ }^{12-14}$ Some of these old people have low body temperatures even when they are not ill. ${ }^{12}$ Many do not realise that they may be eligible for additional supplementary benefits for extra heating. ${ }^{12} 15$ During the comparatively mild winter of 1972 a random survey was conducted on 1000 elderly people in Britain, ${ }^{12}$ and the authors of the report suggested that about half a million old people might be at risk of hypothermia if their results were extrapolated to the general population. The same research group has now reported ( $p$ 353) on the thermoregulatory function of 47 of the elderly people first studied in 1972. During the ensuing four years the environmental and socioeconomic conditions of these old people had not changed, but the tests showed a progressive impairment of thermoregulation-in particular, decreased vasoconstriction in response to cold.
Cutaneous vasoconstriction can reduce the heat conductivity of the skin to that of cork (once used to plug vacuum flasks), so it is a powerful normal mechanism for conserving heat. Impairment of this reflex makes an old person more liable to become hypothermic despite shivering. The impairment of thermoregulation is probably part of a more widespread dysfunction of the autonomic nervous system in elderly people, for the study showed that orthostatic hypotension was also fairly common.

It seems, then, that many old people cannot conserve the heat they make because they lose it through their skin. ${ }^{16}$ Wearing insulating clothing indoors may help. Half the heat loss from a clothed adult is from the head: there was reason as well as fashion in earlier days for the wearing of nightcaps, smoking caps, and mutches. Mittens or gloves and long underwear should be worn by old people by day and bed socks and extra, warm, dry blankets at night. The metallised "space blankets" on sale for mountaineers are light and very efficient. Not even polar clothing, however, will prevent a normal person in a cold room from losing heat if he remains sedentary, so efforts to provide adequate heating for the elderly and infirm deserve medical support.

${ }^{1}$ Emslie-Smith, D, Lancet, 1958, 2, 492.

2 Duguid, H, Simpson, R G, and Stowers, J M, Lancet, 1961, 2, 1213.

${ }^{3}$ Rosin, A J, and Exton-Smith, A N, British Medical fournal, 1964, 1, 16. Hockaday, T D R, and Fell, R H, British fournal of Hospital Medicine, $1969,2,1083$.

5 Irvine, R E, Practitioner, 1974, 213, 795.

6 Glinoer, D, et al, Acta Clinica Belgica, 1973, 28, 40.

' Nicolas, F, et al, Anesthésie Analgésie Réanimation, 1974, 31, 485.

8 Tolman, K G, and Cohen, A, Canadian Medical Association fournal, 1970, $103,1357$.

9 Weyman, A E, Greenbaum, D M, and Grace, W J, American fournal of Medicine, 1974, 56, 13.

10 Watts, A J, Environmental Research, 1972, 5, 119.

11 Corkhill, R T, et al, British fournal of Preventive and Social Medicine, 1972, 26, 40 .

12 Fox, R H, et al, British Medical fournal, 1973, 1, 200.

13 Williams, B T, Gerontologia Clinica, 1968, 10, 281.

14 Offices, Shops and Railways Premises Act (1963). London, HMSO.

15 DHSS, Help with Heating Costs. London, HMSO, 1974.

16 MacMillan, A L, et al, Lancet, 1967, 2, 165.

\section{Systemic chemotherapy for primary breast cancer}

At the time cancer of the breast is found it is most often a systemic disease, with small non-detectable metastases present. Reports that immediate systemic chemotherapy may delay the clinical manifestations of these disseminated lesions have been regarded as a breakthrough in the management of the disease. ${ }^{1-3}$ Some commentators have maintained that it is not ethical to deny this chance of benefit. ${ }^{4}$

The British Breast Group has expressed the contrary view, ${ }^{5}$ arguing that powerful and potentially harmful chemotherapeutic agents should not be used routinely in the management of a disease which may be associated with long periods of wellbeing until their worth is proved unequivocally and their possible adverse effects fully known. Clearly the value of this treatment needs to be assessed quickly but reliably; the controlled randomised studies that are being set up should also ensure that women taking part have an equal chance of receiving treatment which may benefit them and of avoiding any option which may be unnecessarily distressing. Further- 